\title{
Corrosion Behavior of X80 Pipeline Steel under Thin Electrolyte Layer of Acidic Soil Simulated Solution
}

\author{
Shuaixing Wang ${ }^{1,2, *}$, Daoxin Liu ${ }^{1}, N^{2}$ D ${ }^{2}$, Qing Zhao ${ }^{2}$, Jinhua Xiao ${ }^{2}$ \\ ${ }^{1}$ Institute of Corrosion and Protection, Northwestern Polytechnical University, Xi' an 710072, China \\ ${ }^{2}$ School of Material Science and Technology, Nanchang Hangkong University, Nanchang 330063, \\ China \\ *E-mail: wsxxpg@126.com
}

doi: $10.20964 / 110402534$

Received: 13 January 2016 / Accepted: 1 February 2016 / Published: 1 March 2016

\begin{abstract}
Corrosion behavior of X80 steel under thin electrolyte layer (TEL) of acidic soil simulated solution were studied by utilizing polarization curves, EIS, SEM and XRD. In the bulk solution, cathodic electrochemical reaction governed the corrosion process of X80 steel, and the corrosion rate was higher. Under TEL, the corrosion of X80 steel was greatly affected by TEL thickness. Under TEL of $300 \mu \mathrm{m}$, the corrosion was still related to the cathodic electrochemical process. Under TEL of $145 \mu \mathrm{m}$, oxygen diffusion dominated the corrosion process, and the corrosion rate fluctuated with immersion time. However, the corrosion of X80 steel was jointly affected by the diffusion processes of oxygen and corrosion products under TEL of $70 \mu \mathrm{m}$. In this system, the corrosion rate increased continuously. After $96 \mathrm{~h}$ exposure, the corrosion extent of steel with TEL thickness was in the sequence of $70 \mu \mathrm{m}>$ $300 \mu \mathrm{m}>145 \mu \mathrm{m}$. Complete corrosion product layer was easier to form in the thinner TEL.
\end{abstract}

Keywords: X80 steel; Acidic soil; Corrosion; Thin electrolyte layer (TEL); EIS

\section{FULL TEXT}

(C) 2016 The Authors. Published by ESG (www.electrochemsci.org). This article is an open access article distributed under the terms and conditions of the Creative Commons Attribution license (http://creativecommons.org/licenses/by/4.0/). 